\title{
FERTILIZAÇÃO ORGÂNICA COM CARBONO NO CULTIVO INTENSIVO EM VIVEIROS COM SISTEMA DE BIOFLOCOS DO CAMARÃO BRANCO LITOPENAEUS VANNAMEI
}

\author{
CHARLES FRÓES ${ }^{1}$, GERALDO FÓES ${ }^{1}$, DARIANO KRUMMENAUER ${ }^{1}$, EDUARDO BALLESTER ${ }^{2}$, LUIS HENRIQUE POERSCH ${ }^{1}$, \\ WILSON WASIELESKY JR ${ }^{1}$ \\ ${ }^{1}$ Universidade Federal do Rio Grande - Instituto de Oceanografia, estação Marinha de Aquacultura, Rua do Hotel 2, Cassino, Rio Grande - RS \\ - Brasil. CEP: 96210-030 - charlesfroes@gmail.com \\ ${ }^{2}$ Universidade Federal do Paraná - Programa de Pós-Graduação em Aquicultura e Desenvolvimento Sustentável - Campus Palotina, Rua \\ Pioneiro, 2153 - Jardim Dallas. Palotina - PR. CEP 85950-000 - elcballester@yahoo.com.br
}

\section{RESUMO}

O presente estudo teve como objetivo avaliar o efeito da fertilização com fonte rica em carbono, no cultivo do Litopenaeus vannamei, em sistema intensivo com renovação mínima de água e na presença bioflocos. Juvenis de $L$. vannamei com peso médio inicial de $0,112 \pm 0,07 \mathrm{~g}$ foram cultivados na densidade de 85 camarões $\mathrm{m}-2$ em 6 viveiros escavados (500 $\mathrm{m}^{2}$ cada) e revestidos com PEAD (geomembrana). No tratamento com fertilização de carbono não houve renovação da água de cultivo. No tratamento controle os camarões foram cultivados sem adição extra de carbono, e renovação de água foi de $10 \%$ por semana. Não houve diferença significativa entre os parâmetros de qualidade de água ( $p>0,05$ ). A sobrevivência e conversão alimentar não apresentaram diferenças significativas entre os tratamentos. Entretanto, os camarões cultivados no tratamento com fertilização de carbono apresentaram peso médio final significativamente maior $(p<0,05)(10,72 \mathrm{~g} \pm 2,12)$ em relação ao controle $(8,45 \mathrm{~g} \pm 2,03)$.

PALAVRAS CHAVE: Biofloco, Litopenaeus vannamei, fertilização de carbono

\section{ABSTRACT}

Carbon addition in intensive culture of white shrimp Litopenaeus vannamei with biofloc

This study evaluated the effects of carbon addition in the water quality and performance of the white shrimp Litopenaeus vannamei reared in a minimal water exchange intensive system with suspended microbial flocs. Juveniles of $L$. vannamei with an initial mean weight of $0.112 \pm 0.07 \mathrm{~g}$ were reared in 6 lined ponds $(500 \mathrm{~m} 2)$ at a density of $85 \mathrm{shrimp} / \mathrm{m} 2$. Two treatments with tree replicates each were applied - TM (Molasses treatment) and TC (Control Treatment). Ponds from the Molasses treatment were organically fertilized with molasses (as a carbon source) every week and no water exchange was performed. At the ponds from the control treatment shrimp were reared without molasses addition and water was exchange at a $10 \%$ rate every week. Aeration was provided to all tanks with a $1 \mathrm{hp}$ paddle wheel aerators (equivalent to $20 \mathrm{hp}$ per hectare). The physical and chemical water quality factors were within the recommended range for this species culture and there were no significant differences between treatments throughout the experimental period. Similarly, survival and feed conversion rate did not show significant differences between treatments $(p>0.05)$. However, shrimp reared in the Molasses treatment achieved significant higher $(p<0.05)$ mean final weight $(10.72 \pm 2.12 \mathrm{~g})$ than shrimp reared in the control treatment $(8.45 \pm 2.03 \mathrm{~g})$.

KEYWORDS: Biofloc, Litopenaeus vannamei, intensive culture, carbon addition

\section{INTRODUÇÃO}

Entre as diversas espécies produzidas na aquicultura, o cultivo de camarões marinhos em nível mundial apresentou rápido crescimento nas ultimas décadas (FAO 2009). Atualmente, o camarão branco Litopenaeus vannamei (Boone) é a espécie mais cultivada do mundo (FAO 2009).

Em sistemas de produção intensivos a produtividade pode alcançar até $40000 \mathrm{~kg}$ ha-1 ano-1 (Tacon et al. 2002). Entretanto, um dos maiores problemas destes sistemas é a deterioração da qualidade da água, devido ao acúmulo de compostos nitrogenados tais como a amônia (NH3+-NH4+), nitrito (NO2-) e nitrato (NO3-) (Colt \& Armstrong 1981). Este problema gera preocupação quanto a sustentabilidade ecológica devido a descarga de efluentes ricos em nutrientes nas águas costeiras (Naylor et al. 2000; Burford et al. 2003), obrigando um maior controle sobre a biossegurança e tratamento dos efluentes gerados nestes sistemas de cultivo
(Tacon et al. 2002). Diante deste contexto, tornam-se necessárias mudanças nas estratégias de manejo para que a qualidade da água dos cultivos possa ser mantida em boas condições e redução de possíveis impactos ambientais. Em sistemas de produção aquícola, a manipulação da comunidade microbiana pode trazer benefícios tanto ambientais como econômicos (Ballester et al. 2007; Azim et al. 2008). Pesquisas atuais têm demonstrado que os sistemas super intensivos sem renovação de água podem, através da presença de uma biota bacteriana predominantemente aeróbica e heterotrófica, contribuir para a manutenção da qualidade da água do cultivo e ainda disponibilizar alimento para os organismos cultivados. Estas bactérias têm a capacidade de sintetizar proteínas a partir do carbono orgânico e da amônia. No entanto, é fundamental que a razão carbono: nitrogênio (C:N) seja adequada para sua utilização. Segundo Avnimelech (1999), o 
CHARLES FRÓES, GERALDO FÓES, DARIANO KRUMMENAUER, EDUARDO BALLESTER, LUIS HENRIQUE POERSCH, WILSON WASIELESKY JR

aumento da razão carbono-nitrogênio torna o processo de retirada do nitrogênio inorgânico através de bactérias heterotróficas mais eficiente que a nitrificação, diminuindo rapidamente as concentrações de amônia dissolvida (Azim \& Little 2008).

Os sistemas de cultivo sem renovação ou com mínima renovação de água baseiam-se em viveiros altamente oxigenados e fertilizados com fontes ricas em carbono com objetivo de estimular o surgimento de uma comunidade bacteriana predominantemente heterotrófica, a qual tem capacidade de assimilar os compostos nitrogenados e transformá-los em proteína microbiana (Avnimelech 2009). Neste meio, ocorre a formação de agregados bacterianos, protozoários, metazoários, microalgas, cianobactérias, larvas de invertebrados, fezes, restos de animais mortos e exoesqueletos, os chamados bioflocos (Emerenciano et al. 2007; Ballester et al. 2009). Estes agregados têm grande importância na nutrição dos camarões marinhos (Tacon et al. 2002; Cuzon et al. 2004) e na assimilação dos compostos nitrogenados presentes na água de cultivo, gerados principalmente pela excreção e restos de alimento em decomposição (Gómez-Jiménez et al. 2005).

A reciclagem do nitrogênio em proteína microbiana possibilita melhor desempenho dos camarões em relação ao crescimento, conversão alimentar, resistência a doenças, consumo de ração e sobrevivência dos camarões (Otoshi et al. 2001; Tacon et al. 2002; Wasielesky et al. 2006). Hari et al. (2004), em estudo de adição de carboidratos no cultivo semi-intensivo em viveiros escavados de Penaeus monodon, obtiveram melhores taxas de crescimento e conversão alimentar com adição de farinha de mandioca como fonte de carbono orgânico, com razão C:N de 20:1. Esta razão parece estar bem estabelecida para cultivo do $L$. vannamei cultivado em meio a flocos microbianos, sendo aplicada em diversos estudos com a mesma finalidade (Avnimelech 1999, Hari et al. 2004, Samocha et al. 2007). Segundo Otoshi et al. (2007), uma da vantagens desse sistema é a possibilidade de se produzir $1 \mathrm{~kg}$ de camarão com apenas 160 litros de água, enquanto que para os sistemas convencionais são necessários 64.000 litros para essa mesma produção (Hopkins et al, 1995). Portanto, os benefícios ao meio ambiente são consideráveis quando comparados aos do sistema de produção de camarões tradicional (semi-intensivo), com aproveitamento mais eficiente no uso da água e da terra (Boyd \& Clay 2002). Projetos pilotos realizados em uma fazenda comercial em Belize (Burford et al. 2003; Boyd \& Clay 2002), nos Estados Unidos pelo Waddell Mariculture Center (Wasielesky et al. 2006a; Browdy et al. 2001) e na Estação Marinha de Aquicultura da Universidade Federal do Rio Grande (Wasielesky et al. 2006b, Emerenciano et al. 2007, Ballester et al. 2009; Krumennauer 2011) vêm demonstrando resultados expressivos, com produtividades que variaram entre 20 a 60 toneladas ha-1 e sobrevivências acima de $85 \%$.

Baseado no exposto acima, o presente estudo teve como objetivo avaliar o efeito da fertilização orgânica na qualidade de água, crescimento e sobrevivência do camarão branco $L$. vannamei cultivado em um sistema intensivo com mínima renovação de água na presença de flocos microbianos.

\section{MATERIAIS E MÉTODOS}

O experimento foi realizado na Estação Marinha de Aquacultura "Professor Marcos Alberto Marchiori" do Instituto de Oceanografia da Universidade Federal do Rio Grande (EMA/IO/FURG), situada na cidade do Rio Grande, estado do Rio Grande do Sul, Brasil.

\section{Unidades experimentais e condições ambientais}

O experimento teve a duração de 117 dias. Póslarvas com peso inicial de 0,112 g $( \pm 0,07)$ foram estocadas a uma densidade de 85 camarões $\mathrm{m}-2$, em seis viveiros escavados e revestidos com geomembrana de polietileno de alta densidade. Os viveiros, com área de $500 \mathrm{~m}^{2}$, foram cheios com água marinha costeira (salinidade 33). Foi utilizada aeração artificial permanente ( 24 horas) através de aeradores tipo paddle wheel, na potência de $20 \mathrm{hp}$ ha-1 por viveiro.

O delineamento experimental foi constituído por dois tratamentos: o primeiro com fertilização orgânica de Carbono (melaço) e sem renovação de água e o segundo sem fertilização de carbono de orgânico e mínima renovação de água (10 \% semana-1). Houve três repetições para cada tratamento, os viveiros 
foram povoados e escolhidos aleatoriamente para a fertilização, na qual foi utilizado melaço de cana como fonte rica em carbono. Na primeira semana de experimento os viveiros foram fertilizados com melaço a uma razão de carbono/nitrogênio de 30:1, após esta fase inicial, os viveiros foram fertilizados a fim de manter uma razão de 10:1 os dados foram estimados conforme dados apresentados por Samocha et al. (2007) e Tacon (1987)

No tratamento com fertilização de carbono não foi feita a renovação de água, apenas a reposição da água perdida por evaporação, aproximadamente 10\% do volume total.

\section{Análises físico-químicas}

As determinações de temperatura, $\mathrm{pH}$ e oxigênio foram realizadas diariamente em cada unidade experimental, às 9:00 e 17:00 horas, através de um pHmetro (modelo $\mathrm{DMpH}-1$, Digimed) e oxímetro (modelo Handylab OXI/SET, Schott), respectivamente. A salinidade e as concentrações de amônia total, nitrito, nitrato e fosfato foram medidas a cada três dias. A amônia foi determinada pelo método da UNESCO (1983), o nitrito pelo método de Bendschneider \& Robinson (1952), o nitrato e o fosfato conforme descrito em Aminot e Chaussepied (1983) e a salinidade através de um refratômetro óptico (Atago).

\section{Manejo experimental}

Os camarões foram alimentados duas vezes ao dia (10 e 18 horas), com ração comercial (Potimar 38, da Guabi Ltda). Segundo o fabricante, esta era composta por proteína bruta $( \pm 38 \%)$, extrato etéreo $(>7,5 \%)$, umidade $(<10,0 \%)$, fibra bruta $(<5,0 \%)$, cinzas $(<13,0 \%)$, cálcio $(<3,0 \%)$ e fósforo $(>1,45 \%)$. A taxa de arraçoamento inicial foi de $50 \%$ da biomassa de camarões, sendo este valor ajustado até $2 \%$ no final do período de produção, de acordo com o consumo e as tabelas de Jori et al. (2001). Foram utilizadas bandejas de alimentação para determinar o consumo.

\section{Parâmetros analisados}

No início do experimento, 200 camarões foram selecionados ao acaso e pesados individualmente para cálculo do peso médio inicial. Após o início do experimento, 100 indivíduos de cada unidade experimental foram pesados a cada 15 dias, em uma balança de precisão da marca Toledo do modelo Ohaus Adverture Pro, sendo devolvidos ao tanque de origem após a pesagem.

O ganho de peso dos camarões de cada unidade experimental foi obtido pela seguinte fórmula: Ganho de peso $(\mathrm{g})$ = peso médio final $(\mathrm{g})$ - peso médio inicial $(\mathrm{g})$.

A taxa de crescimento semanal foi calculada de acordo com Bagenal (1978), utilizando a seguinte fórmula: $\mathrm{G}(\mathrm{g} /$ semana $)=(\mathrm{Wf}(\mathrm{g})-\mathrm{Wi}(\mathrm{g})) \times 100 / \mathrm{NS}$, onde Wf representa o peso final, Wi o peso inicial e NS o número de semanas do experimento.

A conversão alimentar aparente (CAA) foi obtida pela seguinte fórmula: $\mathrm{CAA}=$ alimento oferecido (g) / incremento de biomassa (g).

A sobrevivência foi calculada através da seguinte fórmula: $S(\%)=$ (peso total $(\mathrm{g}) /$ peso individual $(\mathrm{g})) \times 100$. Os dados de sobrevivência foram transformados (arco-seno da raiz quadrada) antes da análise estatística.

A cada sete dias foram coletadas amostras de água dos viveiros para determinação da concentração de clorofila a, e peso seco dos bioflocos (MS) e sólidos sedimentáveis. Para a extração do pigmento fotossintético, foi utilizada acetona 90\% (Merck ${ }^{\circledR} \mathrm{PA}$ ), no escuro, a $-12 \stackrel{\circ}{ } \mathrm{C}$ por 24 horas. A concentração da clorofila a foi determinada por fluorimetria (Welschmeyer 1994), e o material em suspensão determinado pelo peso dos filtros de fibra de vidro (GF/F $47 \mathrm{~mm}$ ) antes e após a filtração do material em suspensão. Para o volume de sólidos sedimentáveis ( $\mathrm{ml} \mathrm{L-1)}$ foram utilizados cones Imhoff, onde amostras de um litro de água foram colocadas por vinte minutos, e posteriormente foi feita a leitura do volume sedimentado (Avnimelech 2007).

\section{Análise dos dados}

Depois de verificada a homocedasticidade e normalidade, os dados foram verificados com análise de variância (ANOVA) univariada e posteriormente, com teste de Tukey. As diferenças foram consideradas significativas ao nível de $95 \%$. Os resultados são apresentados como média e desvio padrão ( \pm DP).

\section{RESULTADOS}

Os parâmetros de qualidade da água (temperatura, 
CHARLES FRÓES, GERALDO FÓES, DARIANO KRUMMENAUER, EDUARDO BALLESTER, LUIS HENRIQUE POERSCH, WILSON WASIELESKY JR

salinidade, pH, oxigênio dissolvido, transparência, sólidos suspensos totais, volume do floco, compostos nitrogenados) e clorofila $\alpha$, não apresentaram diferenças significativas entre os tratamentos (Tabela 1).

TABELAS 1 - Valores médios ( $\pm D P)$ das variáveis físico - químicas de qualidade de água e volume de água utilizado, nos viveiros de cultivo intensivo, do camarão branco Litopenaeus vannamei, tratados com ou sem fertilização de carbono orgânico.

\begin{tabular}{|c|c|c|}
\hline \multirow{2}{*}{ Parâmetros } & \multicolumn{2}{|l|}{ Tratamentos } \\
\hline & Com adição de $C$ & Sem adição de $C$ \\
\hline Temperatura $\left(C^{\circ}\right)$ a.m. & $24,3 \pm 1,2$ & $25,4 \pm 1,61$ \\
\hline Temperatura $\left(C^{\circ}\right)$ p.m. & $28,3 \pm 2,71$ & $27,7 \pm 1,87$ \\
\hline $\mathrm{pH}$ & $8,56 \pm 0,83$ & $8,61 \pm 0,94$ \\
\hline Oxigênio Dissolvido(mg L-1) a.m & $5,28 \pm 1,31$ & $5,11 \pm 1,23$ \\
\hline Oxigênio Dissolvido(mg L-1) p.m & $8,36 \pm 2,23$ & $7,98 \pm 2,51$ \\
\hline Secchi $(\mathrm{cm})$ & $18,7 \pm 2,2$ & $27,6 \pm 3,32$ \\
\hline SST (mg L-1) & $168,3 \pm 68,12$ & $111,02 \pm 44,6$ \\
\hline VF (ml L-1) & $36,7 \pm 12,3$ & $30,21 \pm 15,6$ \\
\hline Clorofila $\alpha(\mu g \mathrm{~L}-1)$ & $157,3 \pm 22,32$ & $180,34 \pm 35,1$ \\
\hline Amônia (N-AT mg L-1) & $0,21 \pm 0,09$ & $0,34 \pm 0,11$ \\
\hline Nitrito (N-NO2 mg L-1) & $1,15 \pm 0,7$ & $1,65 \pm 0,9$ \\
\hline Nitrato (N-NO3 mg L-1) & $2,65 \pm 1,31$ & $2,3 \pm 0,9$ \\
\hline Fosfato (P-PO4 mg L-1) & $1,17 \pm 0,21$ & $1,25 \pm 0,31$ \\
\hline Volume de água (m-3) & $523 \pm 35,4$ & $1335 \pm 200,59$ \\
\hline
\end{tabular}

O tratamento com fertilização de carbono orgânico resultou na maior sobrevivência, com média de $96,3 \%$ (Tabela 2). No entanto, não apresentou diferença significativa do tratamento sem fertilização, a qual apresentou $94,2 \%$ de média.

TABELA 2 - Peso médio final, sobrevivência, conversão alimentar aparente (CAA), taxa de crescimento especifico diário (G\%), biomassa final e produtividade, do camarão branco Litopenaeus vannamei, cultivado em viveiros com e sem fertilização de Carbono orgânico.

\begin{tabular}{lcccccc}
\hline Camarões $/ \mathrm{m}^{2}$ & Peso final $(\mathrm{g})$ & Sobrevivência (\%) & CAA & $\begin{array}{c}\text { Ganho de peso } \\
\text { semanal }(\mathrm{g})\end{array}$ & $\begin{array}{c}\text { Produtividade } \\
(\mathrm{kg} \mathrm{m}-2)\end{array}$ & Produtividade (kg ha) \\
\hline Com adição & $10,72 \pm 2,12 \mathrm{a}$ & $96,27 \pm 4,35 \mathrm{a}$ & $1,01 \pm 0,1 \mathrm{a}$ & $0,63 \pm 0,08 \mathrm{a}$ & $0,87 \pm 0,026 \mathrm{a}$ & $8772,12 \pm 26,1$ \\
Sem adição & $8,45 \pm 2,03 \mathrm{~b}$ & $94,20 \pm 3,5 \mathrm{a}$ & $1,22 \pm 0,07 \mathrm{a}$ & $0,50 \pm 0,08 \mathrm{~b}$ & $0,67 \pm 0,041 \mathrm{a}$ & $6759,15 \pm 41,3$ \\
\hline
\end{tabular}

Letras sobrescritas diferentes na mesma coluna indicam diferenças significativas $(p<0,05)$.

Ao final dos 117 dias de experimento, os camarões cultivados nos viveiros fertilizados com carbono apresentaram peso médio final de $10,72 \mathrm{~g}$, valor significativamente superior que os indivíduos cultivados nos viveiros que não foram fertilizados, os quais alcançaram peso médio final de $8,45 \mathrm{~g}$. 


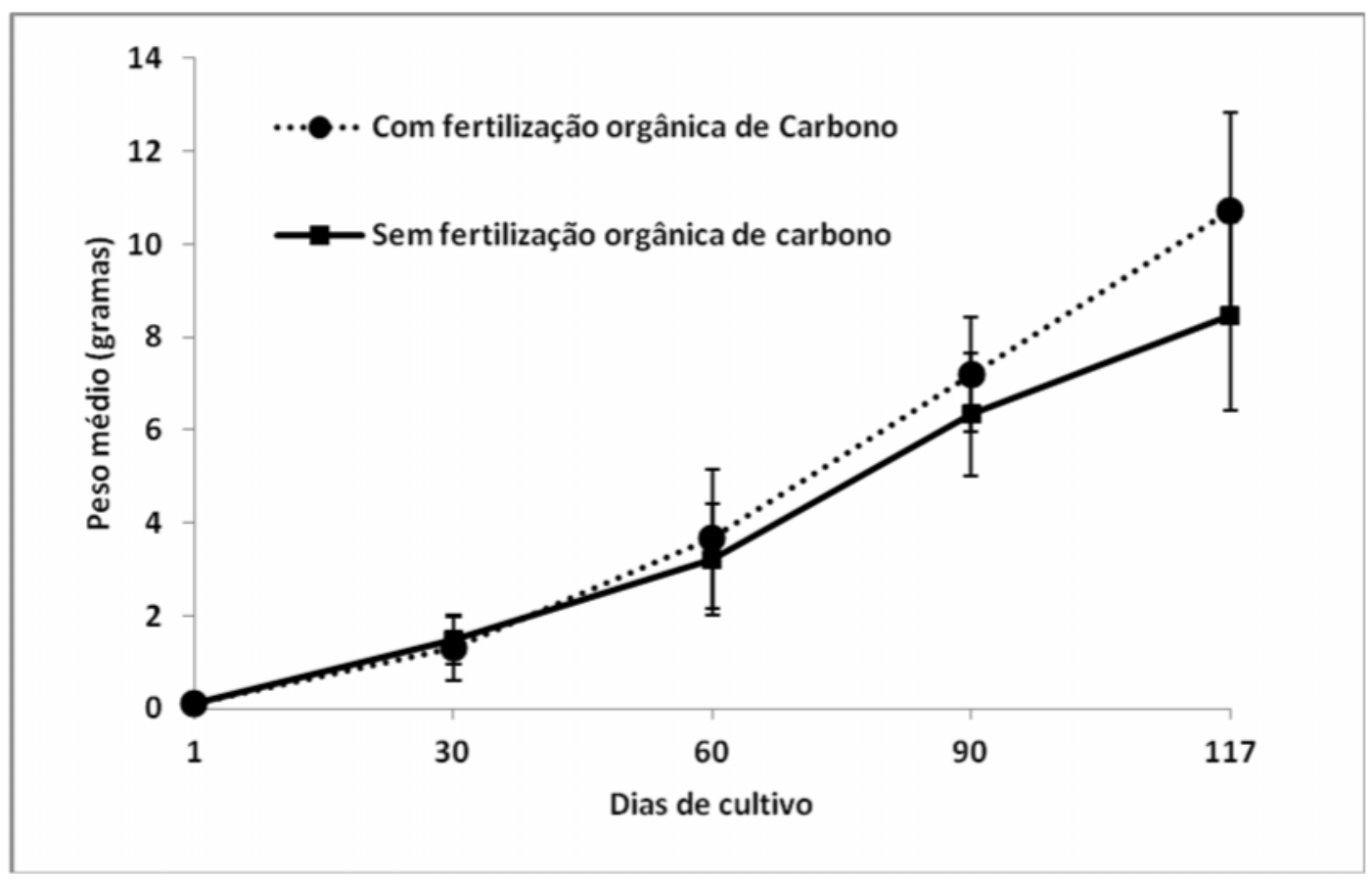

FIGURA 1 - Crescimento do Litopenaeus vannamei cultivado em viveiros intensivos, com e sem fertilização orgânica de carbono.

Os valores de conversão alimentar aparente (CAA) não apresentaram diferença estatística entre si, com médias de 1,01: 1 e 1,22: 1 para os tratamentos com e sem fertilização de carbono, respectivamente.

A maior produtividade alcançada foi de $0,87 \mathrm{~kg}$ $\mathrm{m}-2$ nos viveiros fertilizados com carbono, não tendo diferença estatística ao tratamento sem fertilização que apresentou produtividade de $0,67 \mathrm{~kg} \mathrm{~m}^{2}$. Os resultados de produtividade foram de 8772 e $6759 . \mathrm{kg}$ ha-1, respectivamente.

\section{DISCUSSÃO}

A análise das variáveis físico químicas da qualidade de água, registradas durante 0 experimento, indicaram que as condições ambientais do cultivo provavelmente não interferiram na sobrevivência e crescimento dos camarões.

O oxigênio dissolvido pode ser considerado o parâmetro de qualidade de água mais importante nos cultivos intensivos sem renovação de água. Em cultivos com bioflocos sem renovação de água, fatores como a alta densidade de estocagem, elevada quantidade de material sólido em suspensão e o metabolismo microbiano aeróbico, podem contribuir para a diminuição dos níveis de oxigênio dissolvido
(Schryver et al. 2008; Wasielesky et al. 2006a). Além disso, a precipitação destes sólidos suspensos pode gerar acúmulo de lodo no fundo dos viveiros (Hopkins et al. 1994), causando efeitos negativos no sistema de produção (Chapman et al. 1987, McMillan et al. 2003). Os principais impactos gerados sobre a qualidade da água em sistemas heterotróficos descritos por Ebeling et al. (2006) são a produção muito maior de biomassa bacteriana quando comparado com a biomassa de algas em cultivos autotróficos e conseqüente $\mathrm{o}$ aumento do consumo de oxigênio dissolvido.

O valor médio de oxigênio dissolvido foi de 5,28 mg L-1 para o período da manhã e $8,36 \mathrm{mg} \mathrm{L-1}$ no período da tarde, sendo que a concentração mínima observada foi 3,2 mg L-1. Segundo Mugnier \& Soyez, (2005), concentrações de oxigênio dissolvido abaixo de 2,8 mg L-1 provocam hipoxia, podendo prejudicar crescimento e a sobrevivência do $L$. vannamei. Portanto, ambos os tratamentos apresentaram condições ideais de crescimento para a espécie.

Os valores médios de $\mathrm{pH}$ ao longo do experimento foram de 8,56 e 8,61 para os tratamentos com e sem fertilização de carbono, respectivamente. Os valores registrados neste estudo permaneceram dentro da faixa considerada ideal para a espécie, entre 7,0 e 9,0, para melhor crescimento e 
CHARLES FRÓES, GERALDO FÓES, DARIANO KRUMMENAUER, EDUARDO BALLESTER, LUIS HENRIQUE POERSCH, WILSON WASIELESKY JR

sobrevivência em cultivos do L. vannamei (Van Wyk \& Scarpa, 1999).

A temperatura é um dos fatores mais importantes no crescimento dos camarões marinhos. Wyban et al. (1995) relataram que juvenis de $L$. vannamei $(3,9 \mathrm{~g})$ tiveram seu crescimento reduzido abaixo dos $23^{\circ} \mathrm{C}$, comparado à mesma classe de tamanho cultivado em 27 e $30 \stackrel{\circ}{\circ}$. Portanto, as temperaturas médias registradas durante 0 experimento de 24,3 e $25,4 \stackrel{\circ}{\circ}$ pela manhã e 28,3 e $27,7 \stackrel{\circ}{ } \mathrm{C}$ à tarde, para tratamento com e sem fertilização, não proporcionaram o máximo potencial de crescimento dos camarões desta espécie, principalmente nos últimos 27 dias, já no período de outono, quando as temperaturas diminuíram.

O nitrogênio nos sistemas de cultivo provém da decomposição da ração não ingerida e da excreção dos organismos cultivados (Barak et al. 2003). Em ambos os tratamentos a amônia, nitrito e nitrato estiveram abaixo dos níveis de segurança os quais são: 1 mg L-1 N-AT, 25 mg L-1 N-NO3 e 45 mg L-1 N-NO3 (Van Wyk \& Scarpa 1999, Lin \& Chen 2001, Lin \& Chen 2003). No tratamento com adição de carbono orgânico, a amônia total foi mantida em níveis baixos durante todo o experimento, com uma média de $0,21 \mathrm{mg} \mathrm{L}-1$. Provavelmente isto ocorreu devido à ação da comunidade bacteriana que, através da energia do carbono adicionado, utilizou esta fonte de nitrogênio para formar biomassa.

Nos ambientes de cultivo, a remoção da amônia pode ocorrer por meio da nitrificação das conversões de amônia para nitrato, realizada pelas bactérias nitrificantes, e de conversões de amônia para biomassa microbiana, realizada pelas bactérias heterotróficas e também pela assimilação fotoautotrófica das microalgas (Ebeling et al. 2006). Segundo Hargreaves (1997), quando há pequenas concentrações de amônia no meio, as microalgas são mais eficientes na competição por esta substância do que as bactérias nitrificantes. Entretanto, a remoção da amônia do sistema pelas microalgas representa apenas um armazenamento temporário de nitrogênio em forma de proteína celular, visto que eventualmente, as microalgas morrem e o nitrogênio orgânico presente em suas células sofre mineralização pelas bactérias heterotróficas e reciclagem para o sistema, novamente em forma de amônia (Hargreaves 2006)

No tratamento sem adição de carbono, onde foi realizada a renovação de água, os níveis de amônia também foram baixos, com média de $0,34 \mathrm{mg} \mathrm{L-1}$. Sendo assim, é possível supor que as comunidades de bactérias nitrificantes que reduzem amônia em nitrito e nitrato foram estabelecidas e que a renovação de $10 \%$ semanal foi suficiente para manter os níveis de nitrato aceitáveis. Uma possível estratégia para aumentar a capacidade de nitrificação do sistema seria a utilização de substratos artificiais (Bratvold \& Browdy 2000, Ballester et al. 2007).

Ao contrário dos sistemas de cultivo com altas taxas de renovação, onde geralmente o amônio ( $\left.\mathrm{NH}_{4}+\right)$ é a fração nitrogenada dissolvida mais abundante (Lorenzen et al. 1997), nos dois tratamentos o nitrato foi a forma predominante, correspondendo a mais de $55 \%$ do nitrogênio inorgânico dissolvido, indicando que o processo de nitrificação foi eficiente.

De acordo com Samocha et al. (2007), em sistemas fechados de cultivo, a visualização de camadas de espuma flutuantes na superfície da água, bem como de materiais particulados suspensos, indicam o desenvolvimento de flocos microbianos. A concentração dos flocos microbianos no meio de cultivo sofre variações ao longo do tempo, sendo influenciada por fatores como a sua produção, biodegradação e consumo pelos organismos cultivados. No presente estudo, os parâmetros que indicam a quantidade de microorganismos na água de cultivo: transparência, sólidos suspensos totais, volume do floco e clorofila a não apresentaram diferença estatística entre os tratamentos.

Seria esperado que 0 tratamento sem fertilização de carbono apresentasse maiores concentrações de clorofila a. No entanto, níveis altos de material particulado reduzem a penetração de luz e assim a fotossíntese tende a diminuir. Essas partículas provavelmente forneceram substrato para bactérias que competem com o fitoplancton por nutrientes (Vinatea et al. 2010).

O tratamento com fertilização de carbono proporcionou o maior peso médio final, consequentemente a maior biomassa e produtividade por hectare. Isto pode ser explicado pelo fato das bactérias heterotróficas obterem carbono e energia através de compostos orgânicos, enquanto as 
autotróficas absorvem o carbono do CO2 (dióxido de carbono) como sua principal fonte de carbono (MacGraw, 2002).

Wasielesky et al. 2006a reportaram maior média de peso final para $L$. vannamei cultivados com presença de bioflocos, que indivíduos cultivados em água clara. Chamberlain et al. (2001) afirmaram que a composição de células microbianas em flocos suspensos varia muito, dependendo dos microrganismos específicos e das condições sob as quais estes estão crescendo. McIntosh (2000) encontrou $12,5 \%$ de lipídeos na composição do floco microbiano, Zhukova \& Kharlamenko (1999) demonstraram que zooflagelados e ciliados são capazes de sintetizar ácidos graxos poliinsaturados a partir de ácidos graxos mais simples ingeridos pela predação de bactérias, o que pode significar um incremento da qualidade lipídica nos bioflocos. Jory (2001) e Tacon et al. (2002) reportaram que os bioflocos apresentam altos níveis de proteína e outros importantes componentes que suplementam a nutrição dos camarões. Além disto, muitas bactérias heterotróficas podem apresentar propriedades probióticas para os organismos cultivados, produzindo uma maior diversidade de exoenzimas que atuam diretamente na quebra de compostos orgânicos (Moriarty 1997), além de melhorarem a resposta imune, aumentando os efeitos antivirais (Balcazar et al. 2006).

As bactérias heterotróficas aumentam sua biomassa em questão de horas enquanto as autotróficas podem levar dias (Macgraw 2002). No entanto, Hari et al. (2005), destaca que a absorção do nitrogênio inorgânico ocorre somente com uma relação carbono/nitrogênio for maior que 10:1. Esses autores, em experimento com Penaeus monodon, observaram uma comunidade bacteriana com maior nível protéico quando os viveiros foram fertilizados com fontes de carbono, proporcionando menor conversão alimentar e maior taxa de crescimento, diminuindo assim a necessidade do uso de ração e possibilitando utilização de dietas artificiais com baixo nível protéico.

No presente estudo a entrada de carbono e nitrogênio no sistema, por fertilização, foi mantida em uma razão acima de 10:1. Avnimelech (2009) relatam que essa manipulação na relação $\mathrm{C} / \mathrm{N}$ favorece 0 aparecimento de proteína microbiana, de acordo com Chamberlain et al (2001) uma proporção maior que 10:1 aumenta a porcentagem de lipídeos nos microorganismos. Este processo ocorre através da produtividade natural dos viveiros, onde a fertilização com melaço, que é um ingrediente de baixo custo, melhora a qualidade nutricional dos microorganismos, levando por consequência a um melhor aproveitamento da biota natural dos viveiros pelos camarões.

\section{CONCLUSÃO}

A fertilização com uma fonte rica em carbono orgânico (melaço de cana), nos viveiros de cultivo intensivo sem renovação de água do camarão $L$. vannamei, mostrou-se eficiente para um melhor desempenho zootécnico. Os animais cultivados nos dois tratamentos não apresentaram diferença estatística em relação à sobrevivência, conversão alimentar e taxa de crescimento semanal, entretanto foi observado crescimento significativamente maior nos camarões cultivados em tratamento com adição de carbono orgânico.

\section{AGRADECIMENTOS}

Os autores agradecem ao apoio financeiro concedido pelo Conselho Nacional de Desenvolvimento Científico e Tecnológico (CNPq), Ministério da Pesca e Aquicultura (MPA) e da Coordenação de Aperfeiçoamento de Pessoal de Nível Superior (CAPES). Wilson Wasielesky Junior e Luis Henrique Poersch são bolsistas de produtividade do CNPq.

\section{REFERÊNCIAS}

AMINOT, A \& M CHAUSSEPIED. 1983. Manuel des analyses chimiques em milieu marin. Brest: CNEXO. 395p.

AOAC. 1984. Official methods of analysis. Arlington. Washington, Association of Official Analitycal Chemists. 1141p.

AVNIMELECH, Y. 1999. Carbon/nitrogen ratio as a control element in aquaculture systems. Aquaculture, 176: 227-235.

AVNIMELECH, Y. 2007. Feeding with microbial flocs by tilapia in minimal discharge bio-flocs technology ponds. Aquaculture, 264: 140-147.

AVNIMELECH, Y., 2009a. Biofloc technology - A pratical guide book. The World Aquaculture Society, Baton Rouge, Louisiana.

AVNIMELECH, Y., 2009b. ABC of shrimp BFT grow out. In: World Aquaculture 2009, Abstracts. September 25-29, Veracruz, México. p.121.

AZIM, ME, DC LITTLE \& JE BRON. 2008. Microbial protein production in activated suspension tanks manipulating $\mathrm{C}: \mathrm{N}$ ratio in feed and the implications for fish culture. Bioresource 
Technology, 99: 3590-3599.

AZIM, ME, DC LITTLE. 2008. The biofloc technology (BFT) in indoor tanks: Water quality, biofloc composition, and growth and welfare of Nile tilapia (Oreochromis niloticus). Aquaculture, 283: 29-35.

BAGENAL, TB. 1978. Methods of fish production in fresh waters. Oxford, Blackwell Science. 365p.

BALLESTER, LEC, WJ WASIELESKY, RO CAVALLI \& PC ABREU. 2007. Nursery of the pink shrimp Farfantepenaeus paulensis in cages with artificial substrates: Biofilm composition and shrimp performance. Aquaculture, 269: 355-362.

BALLESTER, LC, PC ABREU, RO CAVALLI, M EMERENCIANO, L ABREU \& WJ WASIELESKY. 2009. Effect of practical diets with different protein levels on the performance of Farfantepenaeus paulensis juveniles nursed in a zero exchange suspended microbial flocs intensive system. Aquacult. Nutr., 16(2): 163172.

BENDSCHNEIDER, $K$ \& RJ ROBINSON. 1952. A new spectrophotometric method for the determination of nitrite in seawater. J. Mar. Res., 11: 87-96.

BOYD, CE \& JW CLAY. 2002. Evaluation of Belize Aquaculture, Ltd: A Super intensive Shrimp Aquaculture System. Report prepared under the World Bank, NACA, WWF and FAO Consortium Program on Shrimp Farming and the Environment. Pages 1-17 in Progress for Public Discussion. Published by the Consortium.

BRATVOLD, D \& CL BROWDY. 2000. Effects of sand sediment and vertical surfaces (AquaMatsTM) on production, water quality, and microbial ecology in an intensive Litopenaeus vannamei culture system. Aquaculture, 195: 81-94.

BROWDY, CL, D BRATVOLD, AD STOKES \& RP MCINTOSH. 2001. Perspectives on the application of closed shrimp culture systems. In: Browdy, CL \& DE Jory. (Eds.), The New Wave, Proceedings of the special session on sustainable shrimp culture, Aquaculture. The World Aquaculture Society, Baton Rouge, USA. p. 20-34.

BURFORD, MA, PJ THOMPSON, RH BAUMAN \& DC PEARSON. 2003. Nutrient and microbial dynamics in high-intensive, zeroexchange shrimp ponds in Belize. Aquaculture, 219: 393-411.

CHAMBERLAIN, G, Y AVNIMELECH, RP MCINTOSH \& $M$ VELASCO. 2001. Advantages of aerated microbial reuse systems with balanced $\mathrm{C}: \mathrm{N}$ composition and nutritional value of organic detritus. Global Aquacult. Advoc., June: 22-24.

CHAPMAN, PM, JD POPHAM, J GRIFFIN, D LESLIE \& J MICHAELSON. 1987. Differentiation of physical from chemical toxicity in solid waste fish bioassays. Water Air Soil Pollut., 33: 295-308.

CUZON, G, A LAWRENCE, G GAXIOLA, C ROSAS \& J GUILLAUME. 2004. Nutrition of Litopenaeus vannamei reared in tanks or in pounds. Aquaculture, 235: 513-551.

DECAMP, OE, L CONQUEST, J CODY \& I FORSTER. 2007. Effect of shrimp stocking density on size-fractionated phytoplankton and ecological groups of ciliated protozoa within zero-water exchange shrimp culture systems. J. World Aquacult.Soc., 38: 395-406.

EBELING, JM, MB TIMMONS, \& JJ BISOGNI. 2006. Engineering analysis of the stoichiomtry of photoautotrophic, autotrophic, and heterotrophic control of ammonia-nitrogen in aquaculture production systems. Aquaculture, 257: 346-358.
EMERENCIANO, MG, WJ WASIELESKY, RB SOARES, EC BALLESTER, EM IZEPPI \& CAVALLI, R.O. 2007. Crescimento e sobrevivência do camarão-rosa (Farfantepenaeus paulensis) na fase de berçário em meio heterotrófico. Acta Sci. Biol. Sci., 29: 1-7.

FAO 2008. The state of World Fisheries and Aquaculture. Disponível em: www.fao.org.

FAO 2009. Shrimp fisheries under scrutiny. Disponível em: www.fao.org.

GÓMEZ-JIMÉNEZ, S, ML GONZÁLEZ-FÉLIX, M PEREZVELAZQUEZ, DA TRUJILLO-VILLALBA, IR ESQUERRABRAUER \& R BARRAZA-GUARDADO. 2005. Effect of dietary protein level on growth, survival and ammonia efflux rate of Litopenaeus vannamei (Boone) raised in a zero water exchange culture system. Aquacult. Res., 36: 834840.

HARGREAVES, J, 2006. Photosynthetic suspended-growth systems in aquaculture. Aquacult. Eng., 34: 344-363.

HARI, B, K MADHUSOODANA, JT VARGHESE, JW SCHAMA \& MCJ VERDEGEM. 2004. Effects of carbohydrate addition on production in extensive shrimp culture systems. Aquaculture, 241: 179-194.

HOPKINS, JS, PA SANDIFER, \& CL BROWDY. 1994. Sludge Management in Intensive Pond Culture of Shrimp: Effect of Management Regime on Water Quality, Sludge Characteristics, Nitrogen Extinction, and Shrimp Production. Aquacult. Eng., 13: 1-30.

HOPKINS, JS, PA SANDIFER \& CL BROWDY. 1995. A review of water management regimes which abate the environmental impact of shrimp farming. In: C.L., Browdy, J.S., Hopkins (Eds.), Swimming through roubled water. World Aquaculture Society, Baton Rouge, Louisiana, USA, 13-22.

JORY, DE, TR CABRERA, DM DUGGER, D FEGAN, PG LEE, AL LAWRENCE, CJ JACKSON, RP MCINTOSH, \& J CASTAÑEDA. 2001. A global review of shrimp feed management: Status and perspectives. P.104-152 in: Browdy, C. L., Jory, D. E. (Eds.), The New Wave, Proceedings of the Special Session on Sustainable Shrimp Culture, Aquaculture. The World Aquaculture Society, Baton Rouge, USA.

KRUMMENAUER, D, PEIXOTO S, CAVALLI RO, POERSCH LH, WASIELESKY WJ. 2011. Superintensive Culture of White Shrimp, Litopenaeus vannamei, in a Biofloc Technology System in Southern Brazil at Different Stocking Densities. J. World Aquac. Soc.,Aceito para publicação.

LEMONNIER, H, E BERNARD, E BOGLIO, C GOARANT, J COCHARD. 2004. Influence of sediment characteristics on shrimp physiology: $\mathrm{pH}$ as principal effect. Aquaculture, 240: 297-312.

LIN, YC \& JC CHEN. 2001. Acute toxicity of ammonia on Litopenaeus vannamei (Boone) juveniles at different salinity levels. J. Exp. Mar. Biol. Ecol., 259: 109- 119.

LIN, YC \& JC CHEN. 2003. Acute toxicity of nitrite on Litopenaeus vannamei (Boone) juveniles at different salinity levels. Aquaculture, 224: 193-201.

MACGRAW, WJ. 2002. Utilization of Heterotrophic and Autotrophic Bacteria in Aquaculture. Global Aquacult. Advoc., December: 82-83.

MCINTOSH, D, TM SAMOCHA, ER JONES, AL LAWRENCE, DA MCKEE, S HOROWITZ \& A HOROWITZ. 2000. The effect of a bacterial supplement on the high-density culturing of Litopenaeus vannamei with low-protein diet in outdoor tank 
system and no water exchange. Aquacult. Eng., 21: 215-227.

MCINTOSH, RP. 2000. Changing paradigms in shrimp farming: low protein feeds and feeding strategies. Global Aquacult. Advoc., April: 44-50.

MCINTOSH, BJ. 2001a. Changing paradigms in shrimp farming: establishment ofheterotrophic bacterial communities. Global Aquacult. Advoc., February: 53-58.

MCINTOSH, RP. 2001b. Establishment of heterotrofic bacterial communities. Global Aquacult. Advoc., February: 53-58.

MCMILLAN, JD, FW WHEATON, JN HOCHHEIMER \& J SOARES. 2003. Pumping effect on particle sizes in a recirculating aquaculture system. Aquacult. Eng., 27: 53-59.

MCNEIL, R. 2000. Zero exchange, aerobic, heterotrophic systems: key considerations.

MORIARTY, DJW. 1997. The role of microorganisms in aquaculture ponds. Aquaculture, 151: 333-349.

MUGNIER, C \& C SOYEZ. 2005. Response of the blue shrimp Litopenaeus stylirostris to temperature decrease and hypoxia in relation to molt stage. Aquaculture, 244: 315-322.

NAYLOR, RL, RJ GOLDBURG, JH PRIMAVERA, N KAUTSKY, MC BEVERIDGE, J CLAY, C FOLKE, J LUBCHENCO, H MOONEY \& M TROELL. 2000. Effect of aquaculture on world fish supplies. Nature, 405: 1017-1024.OTOSHI, CA, AD MONTGOMERY, AM LOOK \& SM MOSS. 2001. Effects of diet and water source on the nursery production of pacific white shrimp Litopenaeus vannamei. J. World Aquac. Soc., 32: 243249.

OTOSHI, CA, LR TANG, DV DAGDABAN, CM HOLL, CM TALLAMY, DR MOSS, SM ARCE \& SM MOSS. 2006. Super intensive growout of the pacific white shrimp Litopenaeus vannamei: Recent advances at the oceanic institute. In: proceedings 0 the 6th Internacional conference Recirculating Aquaculture p. 1-5. Virginia Tech University, Blacksburg.

OTOSHI, CA, MS SCOTT, FC NAGUWA \& SM MOSS. 2007. Shrimp Behavior May Affect Culture Performance at Super-Intensive Stocking densities. Global Aquacult. Advoc., April: 67-69.

SAMOCHA, TM, S PATNAIK, M SPEED, AM ALI, JM BURGER, RV ALMEIDA, Z AYUB, M HARISANTO, A HOROWITZ \& DL BROOK. 2007. Use of molasses as carbon source in limited discharge nursery and grow-out systems for Litopenaeus vanammei. Aquacult. Eng., 36, 184-191.
SCHRYVER, PD, R CRAB, T DEFOIRDT, $N$ BOON \& W VERSTRAETE. 2008. The basics of bio-flocs technology: The added value for aquaculture. Aquaculture, 277: 125-137.

TACON, AGJ. 1987. The nutrition and feeding of farmed fish and shrimp - A training manual. The essential nutrients. Brasilia, FAO. 117 p.

TACON, AGJ, JJ CODY, LD CONQUEST, S DIVAKARAN, IP FORSTER \& OE DECAMP. 2002. Effect of culture system on the nutrition and growth performance of Pacific white shrimp Litopenaeus vannamei (Boone) fed different diets. Aquacult. Nutr., 8: 121-137.

UNESCO. 1983. Chemical methods for use in marine environmental monitoring. Paris, Intergovernmental Oceanographic Commission. Paris, France. 53p.

VAN WYK, P \& J SCARPA. 1999. Water quality and management. In: Van Wyk, P. et al. (Eds.). Farming marine shrimp in recirculating freshwater systems. Florida department of agriculture and consumer services, Tallahassee, p. 128-138.

VINATEA L, AO GALVEZ, CL BROWDY, A STOKES, J VENERO, J HAVEMAN, BL LEWIS, A LAWSON, A SHULER \& JW LEFFLER. 2010. Photosynthesis, water respiration and growth performance of Litopenaeus vannamei in a superintensive raceway culture with zero water exchange: Interaction of water quality variables. Aquacult. Eng., 42: 17-24.

WASIELESKY, WJ, H ATWOOD, A STOKS, \& C BROWDY, 2006a. Effect of natural production in a zero exchange suspended microbial floc based super-intensive culture system for white shrimp Litopenaeus vannamei. Aquaculture, 258: 396-403.

WASIELESKY, WJ, M EMERENCIANO, EC BALLESTER, RB SOARES, R CAVALLI, \& PC ABREU. 2006b. Flocos Microbianos: um novo caminho a ser percorrido. Revista Panorama da Aqüicultura, 16: 14-23.

WELSCHMEYER, NA. 1994. Fluorometric analysis of chlorophyll a in the presence of chlorophyll $b$ and pheopigments. Limnol. Oceanogr., 39: 1985-1992.

WYBAN, J, WA WALSH, \& DM GODIM. 1995. Temperature effects on growth, feeding rate and feed conversion of the Pacific white shrimp (Penaeus vannamei). Aquaculture, 138: 267-279.

ZHUKOVA, NV \& VI KHARLAMENKO. 1999. Source of essential fatty acids in the marine microbial loop. Aquat. Microb. Ecol., 17: 153-157.

Submetido - 17/08/2011

Aceito - 15/02/2012 
